This item was submitted to Loughborough's Research Repository by the author.

Items in Figshare are protected by copyright, with all rights reserved, unless otherwise indicated.

\title{
Concentration of personal and household crimes in England and Wales
}

PLEASE CITE THE PUBLISHED VERSION

http://dx.doi.org/10.1017/S0956792510000057

PUBLISHER

(c) Cambridge University Press

VERSION

VoR (Version of Record)

LICENCE

CC BY-NC-ND 4.0

REPOSITORY RECORD

Tseloni, Andromachi, loannis Ntzoufras, Anna Nicolaou, and Ken Pease. 2019. "Concentration of Personal and Household Crimes in England and Wales". figshare. https://hdl.handle.net/2134/15171. 


\section{European Journal of Applied Mathematics}

http://journals.cambridge.org/EJM

Additional services for European Journal of Applied

Mathematics:

Email alerts: $\underline{\text { Click here }}$

Subscriptions: Click here

Commercial reprints: $\underline{\text { Click here }}$

Terms of use : $\underline{\text { Click here }}$

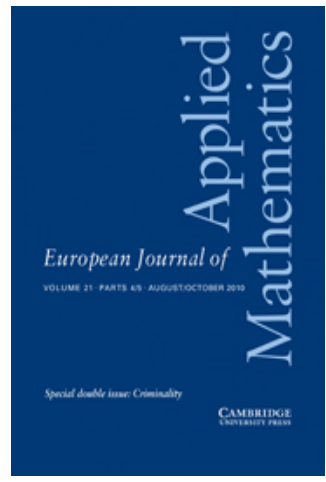

\section{Concentration of personal and household crimes in England and Wales}

ANDROMACHI TSELONI, IOANNIS NTZOUFRAS, ANNA NICOLAOU and KEN PEASE

European Journal of Applied Mathematics / Volume 21 / Special Double Issue 4-5 / October 2010, pp 325 - 348 DOI: 10.1017/S0956792510000057, Published online: 06 April 2010

Link to this article: http://journals.cambridge.org/abstract_S0956792510000057

How to cite this article:

ANDROMACHI TSELONI, IOANNIS NTZOUFRAS, ANNA NICOLAOU and KEN PEASE (2010). Concentration of personal and household crimes in England and Wales. European Journal of Applied Mathematics, 21, pp 325-348 doi:10.1017/S0956792510000057

Request Permissions : $\underline{\text { Click here }}$ 


\title{
Concentration of personal and household crimes in England and Wales
}

\author{
ANDROMACHI TSELONI ${ }^{1}$, IOANNIS NTZOUFRAS ${ }^{2}$, \\ ANNA NICOLAOU ${ }^{3}$ and KEN PEASE \\ ${ }^{1}$ Division of Criminology, Public Health and Policy Studies, Nottingham Trent University, Burton street, \\ Nottingham NG1 4BU, UK \\ email: andromachi.tseloni@ntu.ac.uk \\ ${ }^{2}$ Department of Statistics, Athens Economic University, Patission 76, 10434 Athens, Greece \\ email: ntzoufras@aueb.gr \\ ${ }^{3}$ Department of Business Administration, University of Macedonia, Egantia 156, 54006 Thessaloniki, Greece \\ email: nicolaou@uom.gr \\ ${ }^{4}$ Visiting Professor, Midlands Centre for Criminology and Criminal Justice, University of Loughborough, \\ 19 Withypool Drive, Stockport SK2 6DT, UK \\ email: k.pease@lboro.ac.uk
}

(Received 8 May 2009; revised 20 February 2010; accepted 23 February 2010;

first published online 6 April 2010)

\begin{abstract}
Crime is disproportionally concentrated in few areas. Though long established, there remains uncertainty about the reasons for variation in the concentration of similar crime (repeats) or different crime (multiples). Wholly neglected have been composite crimes when more than one crime types coincide as parts of a single event. The research reported here disentangles area crime concentration into repeats, multiple and composite crimes. The results are based on estimated bivariate zero-inflated Poisson regression models with covariance structure which explicitly account for crime rarity and crime concentration. The implications of the results for criminological theorizing and as a possible basis for more equitable police funding are discussed.
\end{abstract}

\section{Introduction}

The Pareto principle holds that in any population which contributes to a common effect, a relative few of the contributors account for the bulk of the effect. It posits the existence of the 'vital few and the trivial many' (see Juran, 1951). Crime is no exception. A minority of areas contributes disproportionately to the national crime rates while most of the country has very low crime (Nicholas et al., 2007, pp. 115-117; Trickett et al., 1992). For instance, $38 \%$ of the $2006 / 07$ recorded robberies occurred in local authorities serving $8 \%$ of the population (Nicholas et al., 2007, p. 114). This long-established uneven distribution of crimes both across locales and individual households has proved to be of enduring interest (see Forrester et al., 1988, 1990; Osborn et al., 1992; Farrell \& Pease, 1993; Chenery et al., 1996; Ellingworth et al., 1997; Osborn \& Tseloni, 1998; Hope et al., 2001; Bowers et al., 2004; Tseloni, 2006; Hope, 2007).

Understanding crime concentration is necessary for the optimal deployment of police and other resources. This is particularly important at the time of writing, when global recession threatens public sector expenditure in general, and police funding in particular. 
Targeting places and people at greatest risk is a cost-efficient strategy in most public services, expending effort where it is most needed and facilitating the detection of the prolific offenders who specialize in repeating their crimes against the same target (Farrell \& Pease, 2001; Pease, 1998). The reduction of repeated crimes against the same targets accounts for much of crime drop in England and Wales over the past 15 years (Thorpe, 2007). Whether this is a consequence of increasing awareness of the concentration issue is a moot point.

Ones first impulse in devising a deployment strategy for policing would be to ask police officers with local knowledge to anticipate where crime will next occur. The research suggests that they are surprisingly poor in doing so, and that their confidence in prediction is unrelated to their accuracy (see e.g. McLoughlin et al., 2007). Optimal deployment therefore has to depend on a modelling approach.

Previous statistical modelling of crime concentration include the compound Poisson model for property crime counts (Osborn \& Tseloni, 1998; Tseloni, 2006), the 'hurdle' model of the odds of 'single victim versus non-victim' and 'repeat victim versus single' (Osborn et al., 1996) and the bivariate Probit model for joint property and personal crime risks (Hope et al., 2001). This body of research uses the British Crime Survey (BCS) in conjunction with Census information to tap into area level variation. The BCS, unlike police recorded crime, offers a wealth of individual and contextual information (apart from land use) which may help to identify the attributes of high crime areas and their residents. In this respect, prediction is based on area and residents' profiling as the post1992 BCS geography is concealed from the public use file in the interests of interviewee confidentiality. The various forms of crime concentration and the aims of the present work are discussed in the following two sections (Sections 2 and 3). Section 4 provides an overview of the data (see also Hales et al., 2000). Description of area personal and household crime events follows. Sections 6 and 7 present the sets of explanatory variables and the statistical model with explicit application to criminological theory, respectively. Section 8 gives the empirical results and discusses their theoretical implications. An overview and comparisons between observed and fitted crime distributions across area deciles concludes the paper. The Appendix offers preliminary statistical tests of the data.

\section{Components of crime concentration}

The foregoing made clear that addressing crime concentration is central in resource deployment, and has been a driver of recent crime reduction. Designing and implementing informed crime reduction policies can be aided by teasing out the elements which, taken together, comprise chronic victimisation of the same people. Multiple crimes refer to the recurrence of distinct victimisation events, each of a different type, against the same target, for example, a bike theft followed by a burglary. Repeats denote repetition of crime incidents of the same type, for instance three separate incidents of violence. Although early victimisation research employed the terms interchangeably (see, for instance, Hindelang et al., 1978; Reiss, 1980) it is now common practice, not least in the Home Office (the Ministry concerned with crime in England and Wales and its prevention) to present and analyse them separately (Nicholas et al., 2007). Series, whereby victims report a number of incidents of the same nature and believed by the victim to be probably the work of 
the same perpetrator(s) (Hough \& Mayhew, 1983), form a component of repeats but are considered separately here because of the particular counting problems which they pose. They are important in their contribution to total crime counts (see e.g. Planty \& Strom, 2007) but will not be discussed further here.

In this study a fourth type of crime concentration which is not dealt with in crime survey analysis is introduced and tested. This is provisionally labelled composite crime. Composite crimes are multi-crime events, wherein more than one offence is committed during the same incident. For instance, a burglary of an occupied property may well involve threat and assault if the burglar comes face-to-face with the residents. This is a single criminal event in which burglary, threat and assault, all took place against the same target, at the same time and almost certainly by the same offender. Similarly, a common technique in car theft involves hooking the keys from inside a home with a hook, thus committing burglary too. Composite crimes can be seen as a special case of multiple crimes, just as series crimes can be seen as a special case of repeats. Offence code classification rules are in place in the BCS to record each event as the most serious offence that occurred during a single reported incident (Hales et al., 2000, p. 26 and Appendix G). But the fact remains that the conventional recording of such incidents under a specific crime category masks other offences that occurred in the same incident. The less serious components of composite crimes are thus entirely invisible in statistics of crime. Thus, composite crimes are unobservable in (survey) crime statistics unless a detailed analysis of victims narratives was undertaken. Their extent can be more economically estimated via statistical modelling rather than examining victim answers to the surveys open ended questions about 'what happened', 'why it happened' etc.

\section{Rationale and aims}

Research on crime concentration is useful for two related reasons. First, circumscribing crime targets by place and time makes it possible to target resources efficiently. Second, clarifying how concentration is patterned amongst crime types helps to understand what are the necessary elements for a crime to be committed, and hence where leverage can be applied in its prevention. The current study expands previous research on area crime concentration via examining whether this is of a single offence type (repeats), a number of crime types which occurred sequentially (multiples) or during the same event (composite crimes). To this end it employs crime measures and a large set of theoretically informed predictors which are drawn from the BCS and the UK Census.

Two substantive research hypotheses are tested here: The first assumes that a specific crime type is associated with a distinct area profile. Coincidence of more than one crime type in an area may thereby be due to similarity of area profiles. This is termed the observed heterogeneity hypothesis in that each offence type is associated with a particular set of area characteristics. Insofar as areas share characteristics associated with different crime types they experience multiple crimes. Thus different crime categories occur in the same areas simply because these share characteristics which facilitate each crime type. Observed heterogeneity may thus result in multiple or repeat events due to the coincidence or diversity of target attributes associated with different crime types. The second hypothesis proposes that various offences are manifestations of a single underlying variable, reflected 
in composite crime. It suggests that different crime categories are intrinsically connected in that some situations and circumstances are favourable elements of the composite crime in combination.

The two aggregate crime categories, personal and household crime, are examined for a most conservative test of the above hypotheses via respective area crime counts. The area is the lowest common unit of analysis for personal and property crimes and their rates are positively correlated across areas. Crime is relatively rare in most of England and Wales and BCS area crime counts have a disproportionate number of zero values (see the next two sections and the final section). To accommodate both attributes of crime (that it is rare but concentrated), we employ the zero-inflated Poisson model which accounts for the excess of no crime areas (zero crimes) and the repetition of crime events. Personal and property crime counts are jointly examined via the bivariate extension of the zeroinflated Poisson model (Wang et al., 2003) which additionally allows for the endogeneity of each crime category and tests for any intrinsic association between the two counts, i.e. composite crime. Although composite crimes in this study refer to households as possible victims of property offences which coincided with personal crimes against their members in the same incident, the unit of analysis is the area.

Put simply, crime is concentrated in areas with measurable characteristics, such as population density. Some area characteristics are expected to be strong correlates of either personal or property crimes thereby predicting repeat victimisation; others may be associated with both therefore predicting multiple crimes; others may be associated with unaccounted and unconsidered multi-crime events. Each type of crime concentration requires distinct prevention policies.

The most obvious original contribution to criminological knowledge is proposing and testing for composite crimes with their implications for crime prevention. As far as we are aware, this is the first attempt to model jointly a type of coincidence of action which arguably reflects crime concentration better (and certainly complements) past efforts of single dependent variable analysis (Tseloni, 2006). The empirical model is informed by recent developments of victimisation theory as it accounts for the endogeneity of different crime types (Hope et al., 2001) as well as crime concentration (Farrell \& Pease, 1993; Pease, 1998) and rarity (Hope, 2007). Finally, a routine in R software to calculate the standard errors of estimated model parameters is proposed (available from the authors).

\section{Data}

The empirical distributions of property and personal crimes and relevant individual and household characteristics for this study have been taken from the 2000 BCS (Hales et al., 2000). The 2000 BCS was conducted by a consortium of the National Centre for Social Research and the Social Survey Division of the Office for National Statistics, on behalf of the Home Office. The BCS has been administered biannually since 1982 and since 2001 on a rotating annual basis. It employs a multi-stage stratified sample, in principle representative of the adult (16 years or older) population of England and Wales living in private accommodation. The sampling frame is the Postcode Address File. One adult (aged 16 or over) from each selected household is randomly chosen by the interviewer, using selection tables. 
The responses of a total of 17,189 respondents (sample size lower than for the full BCS sample for reasons given in the next section) have been aggregated across 905 sampling points. The sampling point which represents quarter postcode sectors is the study's unit of analysis. Each sampling point yielded an average of 17.4 interviews with a minimum of 4 and a maximum of 29. The empirical models reported later explicitly account for the varying number of respondents per sample point via the offset (see (7.3)). In the 2000 BCS respondents were invited to report any victimisation experienced since January 1999. The reference period is thus the 1999 calendar year. Most interviews took place between January and March 2000 (73\% and $69.3 \%$ of the core and total sample, respectively) and the fieldwork was essentially completed by June 2000 (with the last $0.8 \%$ conducted in July 2000) (Hales et al., 2000; Kershaw et al., 2000, p. 113). The survey additionally gathers information on attitudes towards crime, policing, fear of crime etc.

The area characteristics were selected from the 1991 Census Small Area Statistics after standardization and addition of a 5\% error variance by the BCS fieldwork contractor to ensure confidentiality. The 8 year gap between survey and Census data is inevitable as this is the only recent BCS sweep linked to Census and the linkage was done by the BCS fieldwork contractor at a time when the 2001 Census results were not available. It does not however affect this analysis as most factors come from the BCS (see Section 6) and the effects of the few Census variables may be interpreted as the effects of historic attributes on crime rates.

\section{Property and personal crimes}

Crime rates calculated from the BCS Victim Forms are truncated at five events where a series of related victimisation events are reported (see Section 1), following standard Home Office practice (see Kershaw et al., 2000, p. 111) to avoid very atypical households, with very large numbers of series victimisations, distorting overall averages (see Section 2$)^{1}$.

The two aggregates, for personal and household crimes respectively, are examined here. The former comprises common assaults, wounding, robberies, thefts from person and other thefts from person (Hales et al., 2000). Sex offences have been excluded due to small numbers although the BCS tries to avoid systematic underreporting via the use of self-completion modules (Hales et al., 2000). Household crimes include vandalism, burglary (including attempts), theft from dwelling, theft of motor vehicle, theft from motor vehicle and bicycle theft (Hales et al., 2000). The empirical distribution of individual and household crimes per (quarter) post code sector is given as Table 1. The usual BCS household and adult weight have not been applied since we are interested in area aggregates and model selection rather than level or trend estimates. The vast majority of areas $(59.9 \%)$ suffered zero personal crimes and $90 \%$ suffered two or fewer such incidents. Household crimes are more prevalent than personal crimes, being present at $93.9 \%$ of the sampling points. Their distribution however is heavily skewed, with few areas experiencing an extreme number of events.

The concentration, namely the number of incidents per crime-reporting area or the ratio of the national average number of crimes (incidence) over the proportion of areas

1 There are many purposes for which the writers would regard this as indefensible. Chronically victimized households do exist, and to exclude them by convention simply hides a real problem. 
Table 1. Area personal and property crimes $^{*}, \dagger$

\begin{tabular}{|c|c|c|c|c|}
\hline Number of crimes & $\begin{array}{l}\text { Personal Crimes } \\
\text { Percentage of areas }\end{array}$ & & $\begin{array}{l}\text { Household crimes } \\
\text { Percentage of areas }\end{array}$ & \\
\hline 0 & 59.9 & & 6.1 & \\
\hline 1 & 20.4 & & 9.1 & \\
\hline 2 & 9.5 & & 11.3 & \\
\hline 3 & 5.7 & & 10.7 & \\
\hline 4 & 1.7 & & 11.7 & \\
\hline 5 & 1.3 & & 9.7 & \\
\hline 6 & 0.8 & & 6.6 & \\
\hline 7 & 0.3 & & 6.2 & \\
\hline 8 & 0.1 & & 5.2 & \\
\hline 9 & 0.1 & & 4.3 & \\
\hline 10 & 0 & & 3.8 & \\
\hline 11 & 0 & & 2.7 & \\
\hline 12 & 0 & & 2.4 & \\
\hline 13 & 0 & & 2.3 & \\
\hline 14 & 0.1 & & 1.2 & \\
\hline 15 & 0 & & 1.5 & \\
\hline 16 & 0 & & .8 & \\
\hline 17 or more & 0 & & 3.9 & \\
\hline Total number of areas & & & & 905 \\
\hline Maximum crime count & & 14 & & 42 \\
\hline Mean crimes & & 0.8 & & 6.0 \\
\hline Standard deviation & & 1.4 & & 5.2 \\
\hline Skewness & & 2.9 & & 1.9 \\
\hline \multirow[t]{2}{*}{$\begin{array}{l}\text { Crime concentration } \\
\text { (Incidence/prevalence) }\end{array}$} & & 2.0 & & 6.4 \\
\hline & Total areas $(905)$ & $\begin{array}{c}\text { Without no crime } \\
\text { areas }(862)\end{array}$ & & \\
\hline Pearson's $r$ (correlation) & $0.28^{\S}$ & $0.26^{\S}$ & & \\
\hline
\end{tabular}

*Incidents occurred within a 15 min walk from home to respondents who have not moved house in the previous year.

${ }^{\dagger}$ Series incidents are truncated at 5.

†Personal crimes exclude sexual offences.

$\S$ Two-tail $p$-value $<0.01$.

where victims reside (prevalence), of personal and household crimes numbers 2 and 6.4 events, respectively. To what extent do personal and property crimes occur in the same areas? The two crime types have low but statistically significant correlation of about 0.3 (see last line of Table 1). The observed proportion of areas with no crimes by any type $(4.8 \%)$ is likely to be overestimated due to the sampling points with few respondents. This issue is revisited in the concluding sections of the paper.

We are interested in crimes relating to the current dwelling; this is to ensure that the area characteristics used as predictors relate to the place where the crime(s) took place. To this end only crimes which occurred within a 15 min walk distance from victim's home 
are included. For similar reasons respondents who moved during the 2000 BCS reference period (the 1999 calendar year) are excluded from the analysis. The decision to move may be related to property crime victimisation. In England and Wales, particularly, moving is related to higher property crime before and after the move especially for non-home owners (Ellingworth \& Pease 1998). The empirical distributions of personal and household area crime rates are fairly similar between the full sample and the sample employed ('non-movers and within 15 min walk'). Table A1 presents the relevant comparisons and tests probability differences for each count. The rates are only (significantly) different for zero crimes as restrictions inflate zero events and for 2 and 17 or more household crimes. Therefore the restrictions do not introduce serious sampling bias to area personal and property crimes. Most crime happens near the victim's residence and extreme repeat household victimisation is linked to moving house which replicates previous UK evidence.

\section{Victimisation theory, sample and area characteristics}

This study draws on the meso-strain of routine activity theory and social disorganization theory which operates at the macro level. Proponents of the former theory argue that the demographic and socio-economic characteristics of individuals and their households, as well as their everyday routine activities, together determine their exposure to crime (Cohen \& Felson, 1979; Felson, 1998). Routine activities influence individuals' chances of getting into contact with motivated offenders in the absence of effective guardians.

Constructs pertinent to routine activity theory have been taken from the 2000 BCS. The set of individual characteristics which may affect personal victimisation include demographic characteristics (such as sex, age, ethnicity and children in the household), socio-economic characteristics (namely educational attainment, social class, marital status, lone parents, length of residence, tenure, income and car ownership), and routine activities or lifestyle indicators. Lifestyle includes drinking habits, frequency of going to clubs, or pubs, or being out in a weekday. Most of the aforementioned socio-economic variables are also relevant for property crimes. In particular, property crimes are modelled over the same demographic and socio-economic characteristics as personal crimes except educational level and marital status while the number of adults in the household and accommodation type is used. Age in this case should refer to the 'head of household' rather than the respondent. Preliminary analysis showed a high correlation (0.907) between age of respondent and that of the 'head of household', thus the latter is omitted for parsimony. Routine activities for households may be indicated by protection measures, frequency of house empty over a typical week and participation in neighbourhood watch schemes.

All individual variables were originally categorical or binary except age and number of children in the household. They have been aggregated within postcode sector as the percentage of each $(n-1)$ respective qualitative attribute. The mean age and number of children within each postcode sector have been taken. All sample characteristics entered the regression models as standardized values. Therefore a unit increase implies one standard deviation rise over the national average. Table 2 presents the explanatory variables of this study with an indication whether the variable under question is relevant for only one crime type. 
Covariates

Sample characteristics

Demographic

Respondents' mean age
$\%$ Males

$\%$ Ethnic minority

$\underline{\text { Social }}$

$\%$ Single people*

$\%$ Divorced $^{*}$

$\%$ Widowed $^{*}$

Mean number of children under 16

$\%$ Lone parents

$\%$ One adult households ${ }^{\dagger}$

$\%$ Three or more adults ${ }^{\dagger}$

Education $^{*}$

$\%$ A-levels

$\%$ Trade apprenticeships, O-levels etc.

$\%$ Without qualifications

$\underline{\text { Social Class }}$

$\%$ Manual

Tenure

$\%$ Renting privately

$\%$ Social renting

Accommodation type $^{\dagger}$

$\%$ Semi-detached house

$\%$ Terraced house

$\%$ Flat

Economic

$\%$ Household income less than $£ 5,000$

$\%$ Household income $£ 5,000$ to $£ 9,999$

$\%$ Household income over $£ 30,000$

$\%$ Without a car in the household

$\%$ One car in the household

50.6

45.3

4.3

16.8

11.6

12.5

0.3

4.9

31.2

14.19

11.0

28.5

37.17

53.8

$\%$ More than two cars in the household

Area of residence

$\%$ At the same address for less than 2 years

$\%$ At the same address for $2-5$ years

$\%$ At the same address for 5-10 years

$\%$ In neighbourhood watch scheme ${ }^{\dagger}$

$\%$ Urban

Inner city

Lifestyle

$\%$ Away from home less than $3 \mathrm{~h}$ per weekday* $^{*}$

$\%$ Away from home 3-7 h per weekday*

$\%$ Going to pub less than once a week ${ }^{*}$
Standard Minimum,

Deviation Maximum 
Table 2. Cont.

\begin{tabular}{|c|c|c|c|c|}
\hline Covariates & Mean & $\%$ Freqquncy & $\begin{array}{c}\text { Standard } \\
\text { Deviation }\end{array}$ & $\begin{array}{l}\text { Minimum, } \\
\text { Maximum }\end{array}$ \\
\hline$\%$ Going to pub once a week ${ }^{*}$ & 15.2 & & 9.9 & $0,50.0$ \\
\hline$\%$ Going to pub three times a week or more & 7.3 & & 6.9 & $0,36.4$ \\
\hline$\%$ Going to club less than once a week ${ }^{*}$ & 8.4 & & 7.3 & $0,37.5$ \\
\hline$\%$ Going to club once a week ${ }^{*}$ & 2.17 & & 3.7 & $0,20.0$ \\
\hline$\%$ Drinking alcohol daily* ${ }^{*}$ & 16.2 & & 11.2 & $0,77.8$ \\
\hline $\begin{array}{l}\% \text { Drinking alcohol three to four times a } \\
\text { week }^{*}\end{array}$ & 14.0 & & 9.4 & $0,55.6$ \\
\hline$\%$ Drinking alcohol once or twice a week ${ }^{*}$ & 27.6 & & 11.5 & $0,69.2$ \\
\hline $\begin{array}{l}\% \text { Drinking alcohol once a month or more } \\
\text { but less than once a week }\end{array}$ & 16.8 & & 9.9 & $0,60.0$ \\
\hline$\%$ Houses with any protection measures ${ }^{\dagger}$ & 35.7 & & 23.8 & $0,100.0$ \\
\hline$\%$ House empty less than $3 \mathrm{~h}$ a day ${ }^{\dagger}$ & 44.1 & & 15.6 & $0,100.0$ \\
\hline$\%$ House empty $3-7 \mathrm{~h}$ a day ${ }^{\dagger}$ & 30.7 & & 13.1 & $0,80.0$ \\
\hline \multicolumn{5}{|l|}{ Area characteristics (standardised values) } \\
\hline$\%$ Households renting privately & -0.11 & & 0.77 & \\
\hline$\%$ Single adult non-pensioner households & -0.11 & & 0.47 & \\
\hline Poverty $\ddagger$ & -0.15 & & 3.46 & \\
\hline$\%$ Afro-Caribbean & 0.00 & & 0.83 & \\
\hline$\% \operatorname{Asian}^{\S}$ & 0.04 & & 0.91 & \\
\hline$\%$ Population $16-24$ years & -0.04 & & 0.28 & \\
\hline$\%$ Housing association accommodation & -0.05 & & 0.71 & \\
\hline$\%$ Persons moved in last year & -0.06 & & 0.26 & \\
\hline Population density & 0.13 & & 0.93 & \\
\hline \multicolumn{5}{|l|}{ Regions } \\
\hline North & & 7.3 & & 0,1 \\
\hline Yorkshire/Humberside & & 9.3 & & 0,1 \\
\hline North West & & 11.6 & & 0,1 \\
\hline East Midlands & & 8.1 & & 0,1 \\
\hline West Midlands & & 10.1 & & 0,1 \\
\hline East Anglia & & 4.6 & & 0,1 \\
\hline Greater London & & 13.3 & & 0,1 \\
\hline South East (base) & & 14.2 & & 0 \\
\hline South West & & 9.6 & & 0,1 \\
\hline Wales & & 6.7 & & 0,1 \\
\hline
\end{tabular}

"Entered only the set of covariates for personal crimes.

${ }^{\dagger}$ Entered only the set of covariates for property crimes.

${ }^{*}$ Aggregate factor calculated as $(0.859 \times$ percentage lone parent households $+0.887 \times$ percentage households without a car $-0.758 \times$ non-manual $-0.877 \times$ percentage owner-occupied households $+0.720 \times$ mean number of people per room $+0.889 \times$ percentage households renting from a local authority).

${ }^{\S}$ Indian, Pakistani or Bangladeshi.

Social disorganization theory (Shaw \& McKay, 1942; Sampson \& Groves 1989) asserts that crime is determined primarily by community attributes. They contend that the ability of a community to supervise teenage peer groups, develop local friendship networks and 
stimulate residents' participation in local organizations depends on community characteristics. Social disorganization and resulting crime and delinquency rates depend on the neighbourhood's socio-economic status, residential mobility, ethnic heterogeneity, family disruption and urbanization. Such community attributes comprise the macro-level dimensions of victimisation models. As mentioned these constructs have been taken from the 1991 Census and they arguably inform on historic area profiles due to the 8 years gap with the 2000 BCS.

To avoid the problem of multi-collinearity which might have appeared due to the inclusion of correlated variables, an overall poverty factor is included. It was constructed by aggregating the percentage of lone parent households, households without car, the mean number of persons per room, the percentage of households renting from Local Authority, households with non-manual 'head of household', and owner occupied households (Kershaw \& Tseloni, 2005). The percentage of households in housing association accommodation also indicates low economic status, but exhibits a low correlation with the Poverty factor. Other area characteristics may affect residents' victimisation according to the social disorganization theory and previous empirical evidence (Trickett et al., 1995). Private renting rates and resident movement rates can be seen as measures of neighbourhood stability. Racial diversity is indicated by the percentage of Black and Asian (namely Indian, Pakistani, Sri Lankan or Bangladeshi) in an area. Population density is the obvious measure of urbanisation while the percentage of single adult non-pensioner households indicates lack of informal social control in a community. The population profile of a neighbourhood, more specifically the supply of potential offenders, has a proxy in the percentage of the population aged 16-24. Apart from the Census variables we include a BCS-defined nominal variable, region, to capture omitted effects operating at a higher level of aggregation. Regionally, England and Wales is divided into Wales and the nine Government Office Regions of England. The South East is used as the base category in the later empirical models. Two more BCS-defined variables are inner city which is indicated via a dummy variable and the standardized percentage of urban households. All macro indicators originally entered the regressions of property and personal crimes.

\section{Statistical model}

The Poisson distribution is commonly used to model crime counts. It is evident from Table 1 that in the majority of areas no personal crime was reported. The presence of more zeros than expected for the Poisson can be accommodated through a compound probability model for events, namely, the zero-inflated Poisson (ZIP) distribution. The zeros are assumed to arise in two ways corresponding to distinct underlying states or conditions of each area. The first state that an area has no crime occurs with probability $p$ and produces only zeros, while the other state where crime exists, occurs with probability $1-p$ and leads to a standard Poisson count. The bivariate zero-inflated Poisson (BZIP) regression is an extension of the univariate ZIP for the joint analysis of positively correlated counts with excess zeros. Li et al. (1999), Wang et al. (2003), Karlis \& Ntzoufras (2005) and Lee et al. (2005) give formal descriptions of the model and its estimation process. In what follows, we shall discuss the generic structure of a BZIP model in the light of our substantive research questions. 
Let $Y_{1}, Y_{2}$ denote the observed personal and household crime events of an area. We assume that the two dimensional response vector $\left(Y_{1}, Y_{2}\right)$ follows the BZIP distribution

$$
\left(Y_{1}, Y_{2}\right)= \begin{cases}(0,0) & \text { with probability } p \\ B P\left(\lambda_{1}, \lambda_{2}, \lambda_{3}\right) & \text { with probability } 1-p\end{cases}
$$

which is the mixture of a bivariate Poisson distribution $B P\left(\lambda_{1}, \lambda_{2}, \lambda_{3}\right)$ with a degenerate component of point mass at $(0,0)$. The zero-inflation parameter $p$ may be interpreted as the proportion of areas with zero crime. The bivariate Poisson density

$$
f_{\mathrm{BP}}\left(y_{1}, y_{2} ; \lambda_{1}, \lambda_{2}, \lambda_{3}\right)=\sum_{j=0}^{\min \left(y_{1}, y_{2}\right)} \frac{\lambda_{1}^{y_{1}-j} \lambda_{2}^{y_{2}-j} \lambda_{3}^{j}}{\left(y_{1}-j\right) !\left(y_{2}-j\right) ! j !} \exp (-\lambda)
$$

where $\lambda=\lambda_{1}+\lambda_{2}+\lambda_{3}$ is derived by the reduction $Y_{1}=V_{1}+V_{3}$ and $Y_{2}=V_{2}+V_{3}$ of independent Poisson random variables $V_{1}, V_{2}, V_{3}$ with respective means $\lambda_{1}, \lambda_{2}$ and $\lambda_{3}$. These latent or unobservable counts may be interpreted as follows. $V_{1}$ and $V_{2}$ represent events that are strictly personal victimisations and crimes against the household, respectively. The third set of incidents, $V_{3}$, are composite crimes which involve both offences in the same event but perhaps only the most severe was recorded according to standard practice. They should therefore be included in both observed counts.

The marginal distributions of the BZIP are univariate zero inflated Poisson distributions

$$
Y_{k}=\left\{\begin{array}{ll}
0 & \text { with probability } p, \\
\operatorname{Poisson}\left(\lambda_{k}+\lambda_{3}\right) & \text { with probability } 1-p,
\end{array} \quad k=1,2 .\right.
$$

The parameter $\lambda_{3}$ acts additively on the marginal means. It can be verified that

$$
\operatorname{Cov}\left(Y_{1}, Y_{2}\right)=(1-p)\left[\lambda_{3}+p\left(\lambda_{1}+\lambda_{3}\right)\left(\lambda_{2}+\lambda_{3}\right)\right]
$$

For the value $\lambda_{3}=0$ the BZIP distribution reduces to the double zero inflated Poisson (hereafter double ZIP). The latter assumes that there are no distinct events $V_{3}$ and the two broad crime types are linked only due to common areas' profile.

For independently distributed observations $\left(y_{1 i}, y_{2 i}\right), i=1, \ldots, n$ as in (7.1) the observed data log-likelihood function is given by

$$
\ell=\sum_{i=1}^{n}\left[\delta_{i} \log \left(p+(1-p) e^{-\lambda_{i}}\right)+\left(1-\delta_{i}\right)\left[\log (1-p)+\log f_{\mathrm{BP}}\left(y_{1 i}, y_{2 i} ; \lambda_{1 i}, \lambda_{2 i}, \lambda_{3 i}\right)\right]\right]
$$

where $\delta_{i}=1\left(y_{1 i}=0, y_{2 i}=0\right)$ is a indicator function. Using canonical links, we assume that the Poisson means $\lambda_{k}=\left(\lambda_{k 1}, \ldots, \lambda_{k n}\right)^{\prime} k=1,2,3$ depend on covariates via

$$
\log \left(\lambda_{k}\right)=\eta_{k}=\log (N)+X_{k} \beta_{k}, \quad k=1,2,3,
$$

where $X_{1}, X_{2}, X_{3}$ are design matrices incorporating the covariates and $\beta_{1}, \beta_{2}, \beta_{3}$ are the associated vectors of regression coefficients. In the 2000 BCS $i=1,2, \ldots, n, n=905$ is the number of quarter postcode sectors and the offsets $N=\left(N_{1}, \ldots, N_{n}\right)^{\prime}$ are their corresponding sampling sizes. Partly different covariates entered initially the empirical BZIP model of 
household and personal area crimes for each crime type (see the previous section). Region, inner city, all census variables and a subset of sampling characteristics (urban, tenure, lone parent, accommodation type, manual social class, income and children) entered originally the composite crime rate, $V_{3}$.

A double zero inflated Poisson model was also fitted for the pair of correlated responses, namely the personal and household crimes. Formally this is identical to the set of equations (7.3) for $k=1,2$ but not 3. As mentioned above, the double ZIP model assumes that the overlap between the two broad categories of victimisation types is only due to areas' similar characteristics thereby testing the observed heterogeneity hypothesis. If the double ZIP fits the data better than the BZIP model multiple events would not entail composite crimes but would be attributable to common crime correlates between personal and property crimes.

Maximum likelihood estimates of the model parameters can be obtained employing the EM algorithm. For completeness the steps of the algorithm are briefly sketched. Latent indicator variables $Z_{i}$, for $i=1, \ldots, n$, take the values 1 or 0 according to whether the event $\left(Y_{1 i}, Y_{2 i}\right)$ comes from the degenerate zero or the bivariate Poisson component respectively. For $Z_{i}=0$, an additional latent variable $V_{3 i}$ emerges from the derivation of the bivariate Poisson distribution representing the common part between the observed counts $Y_{1 i}$ and $Y_{2 i}$. The complete data in EM terminology consists of $\left(Y_{1 i}, Y_{2 i}, V_{3 i}, Z_{i}\right)$. The complete data likelihood arises from

$$
\prod_{i=1}^{n} P\left(Y_{1 i}=y_{1 i}, Y_{2 i}=y_{2 i} \mid Z_{i}=z_{i}\right) P\left(Z_{i}=z_{i}\right)=\prod_{i=1}^{n} p^{z_{i}}\left[(1-p) f_{\mathrm{BP}}\left(y_{1 i}, y_{2 i} ; \lambda_{1 i}, \lambda_{2 i}, \lambda_{3 i}\right)\right]^{1-z_{i}}
$$

If $\phi=\log (p /(1-p))$ and $\theta$ denotes the entire vector of parameters, the complete data log-likelihood is expressed as $l_{c}(\theta)=l_{c}(\phi)+l_{c}\left(\beta_{1}\right)+l_{c}\left(\beta_{2}\right)+l_{c}\left(\beta_{3}\right)$, where

$$
\begin{aligned}
l_{c}(\phi) & =\sum_{i=1}^{n}\left\{z_{i} \log (p)+\left(1-z_{i}\right) \log (1-p)\right\}, \\
l_{c}\left(\beta_{k}\right) & =\sum_{i=1}^{n}\left\{\left(1-z_{i}\right)\left(-\lambda_{k i}+\left(y_{k i}-v_{3 i}\right) \log \left(\lambda_{k i}\right)-\log \left[\left(y_{k i}-v_{3 i}\right) !\right]\right)\right\}, \text { for } k=1,2, \\
l_{c}\left(\beta_{3}\right) & =\sum_{i=1}^{n}\left(1-z_{i}\right)\left\{-\lambda_{3 i}+v_{3 i} \log \left(\lambda_{3 i}\right)-\log \left(v_{3 i} !\right)\right\} .
\end{aligned}
$$

Should the missing data $\left(v_{3 i}, z_{i}\right), i=1, \ldots, n$, were known the problem of maximizing the complete data log-likelihood is equivalent to maximizing each of the components separately via logistic regression for the first component and weighted Poisson regression for the remaining three. The EM algorithm at each iteration $t$ alternates between two calculations, the E-step and the M-step. Using the current values of the parameters at $t$ iteration of the algorithm, $\theta^{(t)}=\left(\phi^{(t)}, \beta_{1}^{(t)}, \beta_{2}^{(t)}, \beta_{3}^{(t)}\right)$, the E-step requires the calculation of the expectation of the complete data log-likelihood, conditional on the current value of the parameters $Q\left(\theta, \theta^{(t)}\right)=E\left(l_{c}(\theta) \mid \theta^{(t)}\right)$. Noting that the unobserved variables $V_{3 i}$ and $Z_{i}$, $i=1, \ldots, n$ are independent and the complete data log-likelihood is a linear function of 
Table 3. Summary statistics of alternative models of area personal and household crimes $^{a, b}$

Covariates

Model A

Model B

Inflation factor, $\hat{p}$ (standard error)

BZIP Bayesian information criterion

$0.0315(0.007)^{*}$

8,103

$0.0309(0.007)^{*}$

Double ZIP Bayesian information criterion

8,136

8,082

8,113

" $p$-value $<0.01$.

them, $Q\left(\theta, \theta^{(t)}\right)$ may be calculated replacing them with

$$
z_{i}^{(t+1)}=E\left(Z_{i} \mid \theta^{(t)}\right) \quad \text { and } v_{3 i}^{(t+1)}=E\left(V_{3 i} \mid \theta^{(t)}\right)
$$

the exact expressions of the conditional expectations are given respectively by formulae (7) and (8) in Karlis \& Ntzoufras (2005). At the M-step $\theta^{(t+1)}$ is chosen to be the value of $\theta$ which maximizes $Q\left(\theta, \theta^{(t)}\right)$ with respect to its first argument. The estimated BZIP and double ZIP models of household and personal crimes are obtained using the “bivpois' package for R software (Karlis \& Ntzoufras, 2005; Venables et al., 2007). The asymptotic standard errors of the regression coefficients were obtained from the inverse of the observed information matrix. The $\mathrm{R}$ code for their calculation is available from the authors. The final models have been selected via minimising the Bayesian Information Criterion (BIC) (Davidian \& Giltinan, 1995; Greene, 1997). The Akaike Information Criterion (AIC) has not been used because it 'generally favor[s] inclusion of more terms in the model' (Davidian \& Giltiman 1995, p. 207).

\section{Results}

\subsection{Selected models and theory implications}

Two models, i.e. sets of three marginal Poisson regressions, are presented in Tables 3 and 4: Model A includes individual effects of covariates. Model B is identical to Model A except for allowing combination crimes to be associated with inner city and its interaction with population density rather than population density individually (Model A). A number of variables have been omitted from the final models. These include the proportions of single people, one and three or more adult households, one car households, educational attainment, less than 2 years and over 5 years length of residence, households in neighbourhood watch schemes and all lifestyle measures except high pub-going frequency and break-in protection. The Census characteristics which were dropped from the models are the percentage of population 16-24 years old, households with 'head of household' of Asian origin, single adult non-pensioner households, those in housing association accommodation and persons moved in the year prior to the 1991 Census.

The estimated inflation factors, $\hat{p}$, and the values of BIC for each BZIP, i.e. Model A and $\mathrm{B}$, and its respective double ZIP (see the previous section) are displayed in Table 3 . The respective BZIP specification which includes the common latent count, $V_{3}$, fits the data better than the double ZIP for each Model. This statistical result implies that for a very small number of events personal and property crimes occurred concurrently. The 
two aggregate crimes are not simply endogenous, i.e. associated with (partly) similar area characteristics, to a (small) degree they are identical events. The raw BCS data masks this (unless the narratives of the crime incidents are examined via qualitative data analysis). According to the principal offence rule each reported crime incident is recorded as the most serious offence that occurred during the incident (see also the last paragraph of Section 2).

Therefore neither hypothesis set out earlier in this paper is rejected here. Area heterogeneity is delineated in the marginal ZIP regressions for $\hat{\lambda}_{1}$ and $\hat{\lambda}_{2}$ while composite crime also exists as outlined by $\hat{\lambda}_{3}$. The BZIP specification contrasts multiple events which are due to the overlap of area characteristics associated with each crime type and composite crimes. A comparison of the two BZIP specifications shows that Model B has a better fit. It is therefore discussed in the next sections.

The estimated mean number of events $\hat{\lambda}_{k}, k=1,2,3$, for the three marginal distributions of personal, household and composite crimes associated with each covariate for Models $\mathrm{A}$ and $\mathrm{B}$ are given in Table 4. The empirical estimates of the model parameters, $\hat{\beta}_{k}$, of the set of equations (7.3) along with their standard errors are available upon request. The estimated mean number of clearly personal and property crimes in a non-inner city area of South East England with nationally average demographic and socio-economic attributes is 0.7 (calculated as the product of $\hat{\lambda}_{1}$ and the nationally average sampling size of quarter postcode sectors, i.e., $0.04 \times 17.43$ ) and 5.93 (calculated as $0.34 \times 17.43$ ), respectively. The expected counts slightly underestimate the respective observed values of 0.8 and 6.0 personal and property crimes (see Table 1). The estimated mean number of composite crime counts is 0.035 (calculated as $0.002 \times 17.43$ ). Taking composite crimes into account the estimated mean personal crimes are only marginally underestimated perhaps due to sensitivity to inner city and regional differences while the estimated and observed property crime counts are essentially identical.

The empirical models evidence that some characteristics are related to personal crimes (see $\hat{\lambda}_{1}$, second or fifth column of Table 4 ), some to property crimes (see $\hat{\lambda}_{2}$, third or sixth column of Table 4 ) and some to multi-crime events (see $\hat{\lambda}_{3}$, fourth or seventh column of Table 4).

\subsection{Multiple crimes}

Age, private renting, 2-5 years length of residence, inner city and population density are individually associated with each crime type. Insofar that these associations are in the same direction for both crime types the above characteristics identify multiple crime areas. These are similar observed heterogeneity factors whereby areas face multiple, i.e. personal and household, crimes due to coincidence of characteristics which are associated with each aggregate crime type. Areas with low mean population age and relatively stable residence (2-5 years) but high population density and private renting (an indicator of transience) are expected to suffer high personal and high property crime rates. In particular, an increase of mean population age by one standard deviation is associated with $22 \%$ and $9 \%$ respective drops of personal and property crimes. A similar increase of the percentage of households with 2-5 years of residence relates to $18 \%$ and $9 \%$ less personal and property crimes, respectively. By contrast, a standard deviation rise of population density 


\begin{tabular}{|c|c|c|c|c|c|c|}
\hline \multirow[b]{2}{*}{ Covariates } & \multicolumn{3}{|c|}{ Model A } & \multicolumn{3}{|c|}{ Model B (Model A+interaction) } \\
\hline & $\begin{array}{c}\text { Personal } \\
\text { crimes }^{\ddagger}, \hat{\lambda}_{1}\end{array}$ & $\begin{array}{l}\text { Household } \\
\text { crimes, } \hat{\lambda}_{2}\end{array}$ & $\begin{array}{c}\text { Composite } \\
\text { crimes, } \hat{\lambda}_{3} \exp (b)\end{array}$ & $\begin{array}{l}\text { Personal } \\
\text { crimes }^{\ddagger}, \hat{\lambda}_{1}\end{array}$ & $\begin{array}{l}\text { Household } \\
\text { crimes, } \hat{\lambda}_{2}\end{array}$ & $\begin{array}{l}\text { Composite } \\
\text { crimes, } \hat{\lambda}_{3}\end{array}$ \\
\hline \multicolumn{7}{|l|}{ Sample characteristics } \\
\hline \multicolumn{7}{|l|}{ Socio-demographic } \\
\hline Per cent widowed & $1.20^{* * *}$ & - & - & $1.20^{* * *}$ & - & - \\
\hline Mean number of children under 16 & - & $1.07^{* * *}$ & - & - & $1.06^{* * *}$ & - \\
\hline Per cent lone parents & - & - & $1.71^{* * *}$ & - & - & $1.77^{* * *}$ \\
\hline \multicolumn{7}{|l|}{ Tenure } \\
\hline Per cent renting privately & $1.31^{* * *}$ & $1.07^{* * *}$ & $0.22^{* * *}$ & $1.31^{* * *}$ & $1.06^{* * *}$ & $0.20^{* * *}$ \\
\hline Per cent in social renting & - & $1.11^{* * *}$ & - & - & $1.11^{* * *}$ & - \\
\hline \multicolumn{7}{|l|}{ Economic } \\
\hline Per cent with household income $£ 5,000$ to $£ 9,999$ & $0.76^{* * *}$ & - & $2.10^{* * *}$ & $0.76^{* * *}$ & - & $2.02^{* * *}$ \\
\hline Per cent with household income over $£ 30,000$ & $0.77^{* * *}$ & - & $2.11^{* * *}$ & $0.76^{* * *}$ & - & $2.38^{* * *}$ \\
\hline Per cent without a car & $1.25^{* * *}$ & - & - & $1.25^{* * *}$ & - & - \\
\hline Per cent with more than two cars in the household & $1.15^{* * *}$ & - & - & $1.15^{* *}$ & - & - \\
\hline \multicolumn{7}{|l|}{ Lifestyle } \\
\hline$\overline{\text { Per cent going to pub three times a week or more }}$ & $1.16^{* * *}$ & - & - & $1.16^{* * *}$ & - & - \\
\hline Per cent houses with any protection measures & - & $1.05^{* *}$ & - & - & 1.03 & - \\
\hline \multicolumn{7}{|l|}{ Area of residence } \\
\hline Per cent at the same address for $2-5$ years & $0.82^{* * *}$ & $0.92^{* * *}$ & - & $0.82^{* * *}$ & $0.91^{* * *}$ & - \\
\hline Inner city dummy & $0.49^{* * *}$ & $1.30^{* * *}$ & - & $0.44^{* * *}$ & $1.40^{* * *}$ & $2.93^{* * *}$ \\
\hline
\end{tabular}




\begin{tabular}{|c|c|c|c|c|c|c|}
\hline \multirow[b]{2}{*}{ Covariates } & \multicolumn{3}{|c|}{ Model A } & \multicolumn{3}{|c|}{ Model B (Model A+interaction) } \\
\hline & $\begin{array}{l}\text { Personal } \\
\text { crimes }^{\ddagger}, \hat{\lambda}_{1}\end{array}$ & $\begin{array}{l}\text { Household } \\
\text { crimes, } \hat{\lambda}_{2}\end{array}$ & $\begin{array}{c}\text { Composite } \\
\text { crimes, } \hat{\lambda}_{3} \exp (b)\end{array}$ & $\begin{array}{l}\text { Personal } \\
\text { crimes }^{\ddagger}, \hat{\lambda}_{1}\end{array}$ & $\begin{array}{l}\text { Household } \\
\text { crimes, } \hat{\lambda}_{2}\end{array}$ & $\begin{array}{l}\text { Composite } \\
\text { crimes, } \hat{\lambda}_{3}\end{array}$ \\
\hline Per cent urban residents & - & $1.12^{* * *}$ & - & - & $1.11^{* * *}$ & - \\
\hline \multicolumn{7}{|l|}{ Area characteristics } \\
\hline Per cent Afro-Caribbean & - & $0.93^{* * *}$ & - & - & $0.94^{* *}$ & - \\
\hline Per cent households renting privately & - & $1.09^{* * *}$ & - & - & $1.08^{* * *}$ & - \\
\hline Population density & $1.23^{* * *}$ & $1.18^{* * *}$ & $0.67^{* *}$ & $1.23^{* * *}$ & $1.28^{* * *}$ & - \\
\hline Poverty & $1.08^{* *}$ & - & - & $1.08^{* * *}$ & - & - \\
\hline Population density in inner city & & & & - & $0.82^{* * *}$ & $0.43^{* * *}$ \\
\hline \multicolumn{7}{|l|}{ Region (base: South East) } \\
\hline South West & 0.95 & 1.09 & - & 0.94 & 1.09 & - \\
\hline Greater London & $0.71^{*}$ & $0.65^{* * *}$ & - & $0.73^{*}$ & $0.65^{* * *}$ & - \\
\hline East Anglia & $0.63^{*}$ & 0.99 & - & $0.64^{*}$ & 0.98 & - \\
\hline East Midlands & 0.82 & 1.01 & - & 0.82 & 1.02 & - \\
\hline West Midlands & 0.89 & 0.92 & - & 0.87 & 0.92 & - \\
\hline Yorkshire-Humberside & $0.64^{* *}$ & 1.10 & - & $0.64^{* *}$ & $1.11^{*}$ & - \\
\hline North West & 0.90 & 1.02 & - & 0.91 & 1.04 & - \\
\hline North & $0.68^{* *}$ & $0.78^{* * *}$ & - & $0.67^{* *}$ & $0.78^{* * *}$ & - \\
\hline Wales & 0.89 & 0.93 & - & 0.88 & 0.94 & - \\
\hline Intercept & $0.042^{* * *}$ & $0.337^{* * *}$ & $0.002^{* * *}$ & $0.043^{* * *}$ & $0.339^{* * *}$ & $0.002^{* * *}$ \\
\hline
\end{tabular}

*Incidents occurred within a $15^{\prime}$ walk from home to respondents who have not moved house in the previous year.

${ }^{\dagger}$ Series incidents are truncated at 5 events.

*Personal crimes exclude sexual offences.

${ }^{\S}$ Aggregate factor calculated as $(0.859 \times$ percentage lone parent households $+0.887 \times$ percentage households without a car $-0.758 \times$ non-manual

$-0.877 \times$ percentage owner-occupied households $+0.720 \times$ mean number of people per room $+0.889 \times$ percentage households renting from a

local authority).

\#Indian, Pakistani or Bangladeshi.

Two-tailed tests:

${ }^{*} 0.05<p$-value $\leqslant 0.10$.

${ }^{* * *} 0.01<p$-value $\leqslant 0.05$.

${ }^{* * *} p$-value $\leqslant 0.01$. 
or private renting is associated with more personal (by $23 \%$ and $31 \%$, respectively) and property crimes (by $6 \%$ and $28 \%$, respectively).

This set however excludes another common significant factor, inner city location. This is related to higher household (by $40 \%$ ) but lower personal (by 56\%) crimes compared to other area types, therefore it is unlikely to promote multiple crimes, rather repeat household offences. We will return to how inner city relates to crime in the discussion of composite crimes.

\subsection{Repeats}

A number of covariates are correlated with either personal or household crimes thereby predicting repeats and the area's crime specialization. In particular, a standard deviation rise of an area's percentage of divorced or widowed residents, poverty, households without a car or with three or more cars or residents' going to the pub three times per week are associated with higher personal crimes by $24 \%, 20 \%, 8 \%, 25 \%, 15 \%$ and $16 \%$, respectively. A similar increase of the percentage of households with low or high income is however related with a $24 \%$ drop of personal crimes. The negative effect of high income on area's personal crime is expected as affluent households reside in relatively safe areas. The non-intuitive similar effect of $£ 5,000-£ 9,000$ household income however may be justified by low income elderly pensioner households which have very low victimisation risk (Kershaw et al., 2001).

An increase of the percentage of Afro-Caribbean population or males (by one standard deviation) is associated with $6 \%$ and $5 \%$ less property crimes, respectively. A standard deviation rise of the percentages of historic private renting (taken from the 1991 Census), flats, semi-detached and terraced houses, urban, social renting (council housing) households or children in the area is related to more household crimes by $8 \%, 9 \%, 7 \%, 17 \%$, $11 \%, 11 \%$ and $6 \%$, respectively. All the above results except one agree with previous evidence from BCS-based and other empirical literature (for an overview see Tseloni et al., 2002). The evidence however that property crime is adversely related to high proportion of male population should be regarded with caution and requires additional investigation.

\subsection{Composite crimes}

As already mentioned, albeit to a small extent, i.e. 0.035 over and above the mean personal and household crime of a South East non-inner city area with nationally average characteristics, personal and household crimes happen concurrently during multi-crime events. Composite crimes, $\hat{\lambda}_{3}$, are associated with high proportions of lone parents, semidetached houses, flats, low (under $£ 9,999$ ) or high (over $£ 30,000$ ) income households and inner cities with relatively low population density. They are expected to rise by $77 \%, 108 \%$, $114 \%, 102 \%$ and $138 \%$ following respective increases of the above factors by one standard deviation. A similar increase of the percentage of households renting privately is however related to an $80 \%$ drop of composite crime. This result is arguably counter-intuitive but it may be explained by urban development in recent years. High levels of private renting are a feature of inner cities which, unlike strictly commercial city centres, are vibrant places 24/7. The fact that people are out and about at all times facilitates informal 
guardianship. Centrally located rented accommodation is higher priced than suburban one and thus attracts people with certain economic and social characteristics, i.e. single professionals. This result reinforces the above-mentioned negative association between population density in inner cities and crime. Indeed, while inner cities are expected to have $193 \%$ more composite crimes than non-inner city areas, a standard deviation increase of population density within inner cities would drop them by $57 \%$. In effect there is no more composite crime in inner cities with population density just over one and a quarter, 1.27 (calculated as $-\{1.08 /(-0.85)\}$ ), standard deviations above the national average than in other areas. All estimated composite crime parameters are highly significant.

\subsection{Regions and excess zeros}

Region is not a predictor of composite crimes. Some regions have significantly different mean levels of property or personal crimes. For instance, South West and the North have significantly lower personal and property crimes compared to the South East other things being equal. East Anglia fares well on personal crimes while Yorkshire-Humberside have significantly lower personal but higher property crimes than the base region. Since the socio-economic composition of the English regions and Wales differs these results are only an indication of regional crime problems and targeted regional crime prevention should also consider the region's population profile.

The estimated likelihood of zero personal and household victimisations is 0.03 for a non-inner city area of South East with nationally average characteristics and number of selected households within sampling points (17.4). It has been calculated by applying the estimated intercept values of Table 4 and the estimated inflation factor, $\hat{p}$, from Table 3 into equation (7.1). As anticipated (see Section 5) this is lower that the observed probability of zero personal and household crimes (0.048). The difference is due to regional and inner city deviations as well as the model's adjustment for zero crime areas due to the small number of respondents.

\section{Overview}

This study tested two hypotheses for understanding the concurrence of personal and property crimes in residential areas: observed heterogeneity and composite crime. The former proposes that different crimes overlap due to common identifiable area characteristics which are associated with each crime type. The composite crimes hypothesis suggests that different crime types are manifestations of mutli-crime events which are latent due to offence recording practices. The empirical evidence drawn here from the 2000 British Crime Survey via the bivariate zero-inflated Poisson statistical model (with covariance structure) showed that both hypotheses cannot be rejected.

Personal and property crimes occur in the same areas because these areas share the following characteristics: high population density, high private renting, low mean population age and low proportion of households with 2-5 years length of residence. Such areas have multiple crimes. By contrast, the inner city is related to higher household but lower personal crimes compared to other places. Some area characteristics which have been outlined in the previous section are associated with either personal or property crimes. To a small extent (by comparison to identifiable crimes) composite crimes exist, especially in areas with high proportions of lone parent households, semi-detached houses 
or flats, low $(£ 5,000-£ 9,000)$ or high (above $£ 30,000)$ income households, inner cities with low population density and low private renting. The above can be used to identify areas with similar socio-economic and demographic profile for assessing the performance of comparable Crime and Disorder Reduction Partnerships (regional divisions of England and Wales (UK) with respect to crime and crime prevention) and deploying crime prevention efforts where they are most needed. The relationship of private renting to crime, however, needs further investigation as it offers contrasting evidence for composite and multiple crimes.

The current statistical formulation reflects recent criminological knowledge that crimes recur, victims suffer more than one crime types but most people are non-victims (Pease, 1998; Hope, 2007) and offers an elegant approach for estimating the standard errors of the BZIP parameters. Having said that, it is hard to imagine areas (rather than households) with absolutely zero crimes in a year. The observed distributions of crime counts, especially the extreme values of zero and very high repeats, in the earlier Table 1 to some extent reflect sampling variability. The following section employs the models predictions to correct for this.

\section{Area crime concentration}

In this last part the empirical model is used to predict crime rates across areas in order to identify high and low crime areas and their difference. As mentioned the specific location of the areas in England and Wales is concealed (see Sections 1 and 4) but the empirical model can be simulated across the country (inputting the values of the area characteristics which are included in the model across the entirety of quarter postcode sectors) in order to identify risk areas. Due to large error margins the precise ranking of areas with respect to crime rates would be unreliable but ranking them into quartiles can predict high crime areas reasonably well (Lynn \& Elliot, 2000). In this section the distributions of observed (from the raw data) and predicted (from the model) crime rates are ranked by area deciles which are also sufficiently broad.

Trickett et al. (1992) employed the distribution of crime counts across area deciles to demonstrate the inequality and, therefore, non-randomness of area crime concentration. Area crime specialization may be demonstrated via intersecting slopes of personal and property crimes across area deciles while the composite crime hypothesis may be supported via strictly parallel personal and property crime distributions over area deciles. Figure 1 displays observed and predicted property and personal mean crime counts across area deciles of observed household crimes. The worst $10 \%$ of observed property crime areas have on average 17.6 and 1.3 more property and personal crimes, respectively, than the safest $10 \%$. Predicted rates are however strikingly less contrasted between low and high observed property crime areas. Indeed both crime types roughly double between the safest and highest risk areas. This result reflects the adjustment for the size variability of sampling points but it is somewhat misleading as it uses observed rates and groups together areas of very different expected crime rates.

Figure 2 also presents observed and predicted property and personal crime rates but this time across area deciles with respect to predicted property crime. Predicted crimes follow closely the respective observed counts with the exception of the highest crime area decile wherein the latter overestimate the predictions. The $10 \%$ of areas with the 


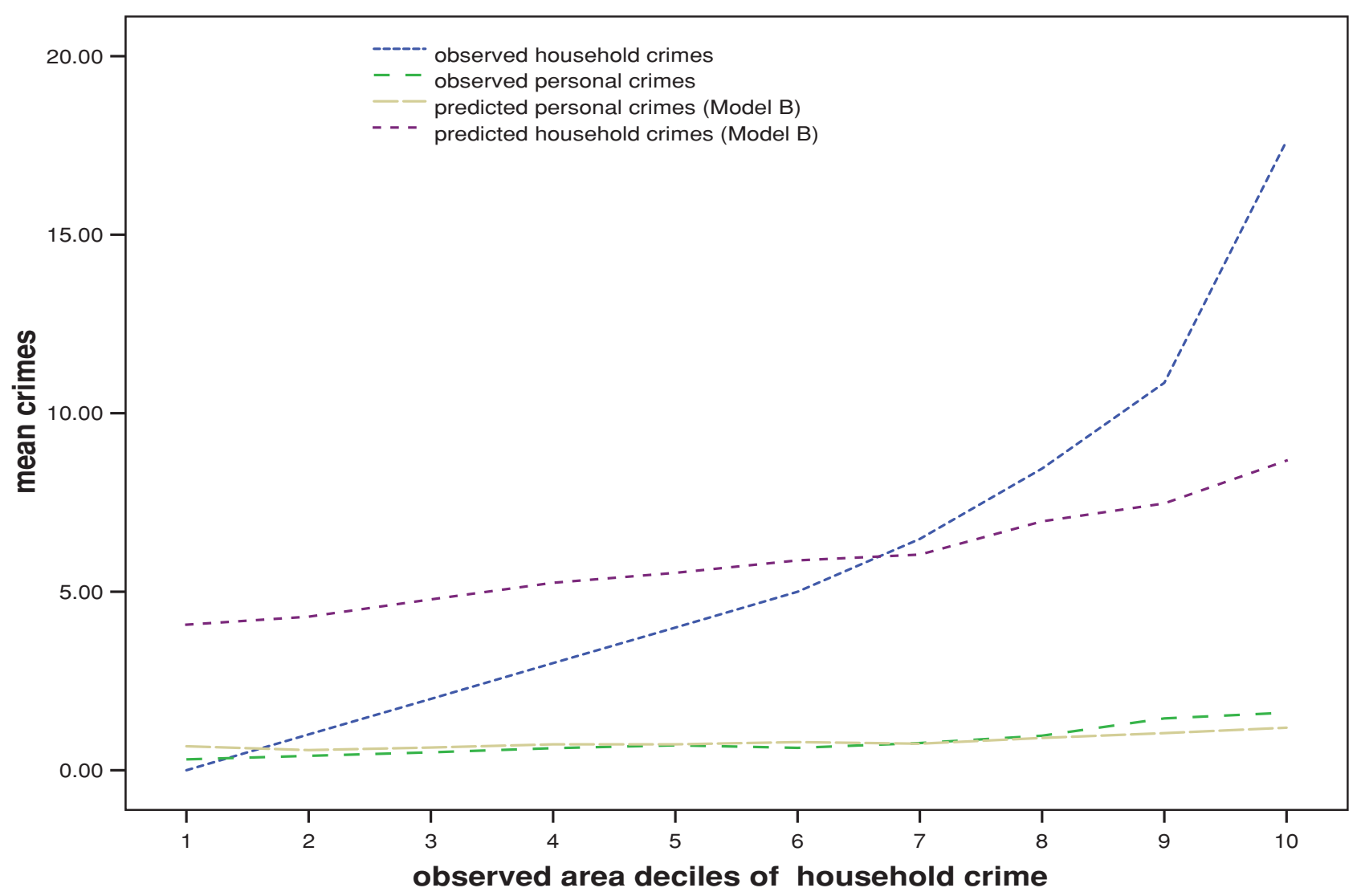

6.1

11.3

9.1

10.7

11.7

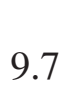

12.8

9.7

9.5

8.8

10.3

FIGURE 1. (Colour online) Household and personal crime rates across area deciles of observed household crime. 


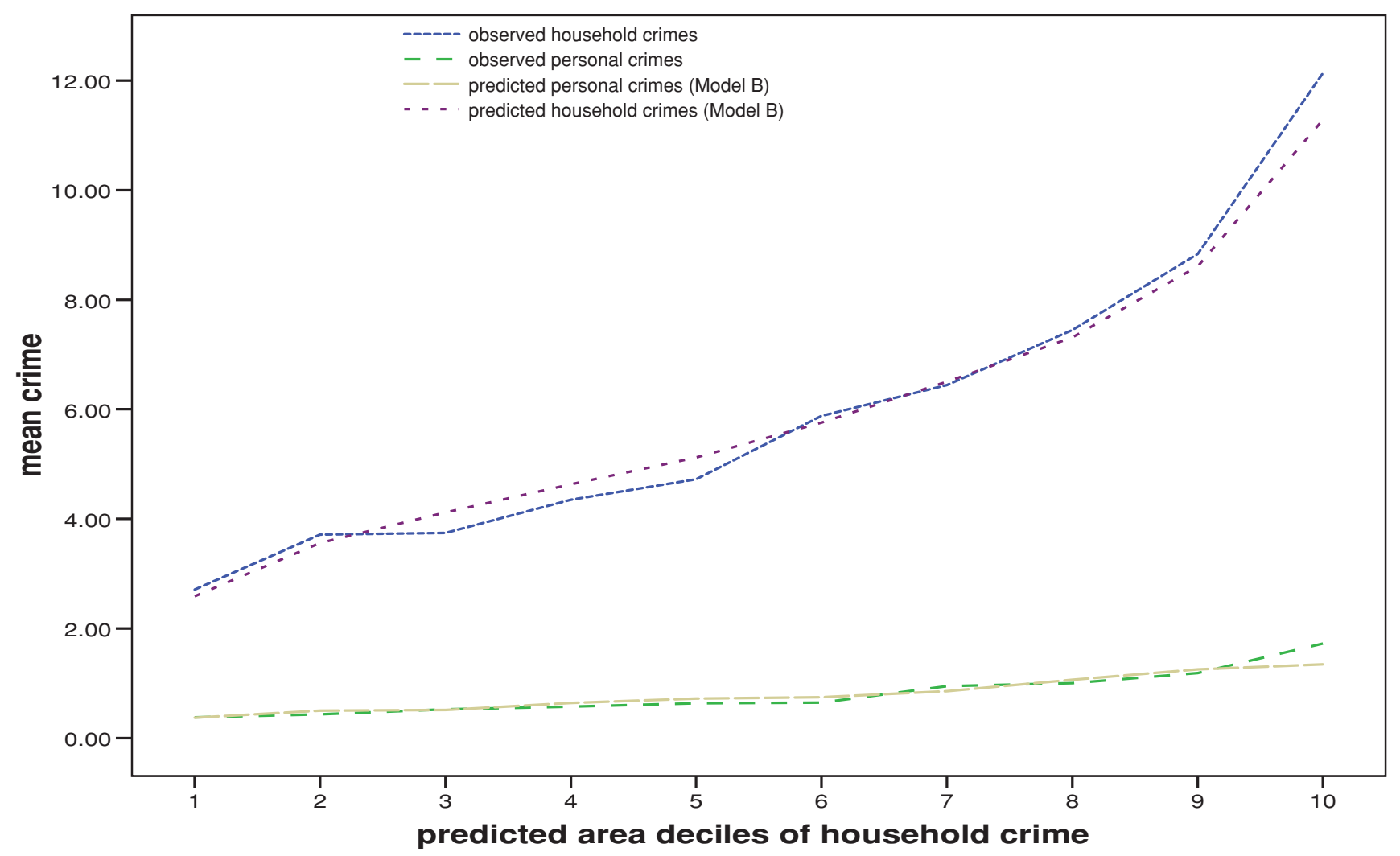

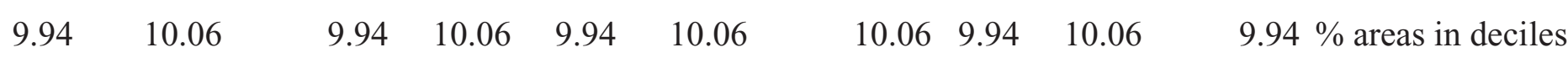

FIGURE 2. (Colour online) Household and personal crime rates across area deciles of predicted household crime. 
Table A1. Complete and 'non-moving \& within 15 minute walk' observed distributions of total household and personal crimes

\begin{tabular}{|c|c|c|c|c|c|c|}
\hline \multirow[b]{2}{*}{$\begin{array}{l}\text { Crime } \\
\text { count }\end{array}$} & \multicolumn{2}{|c|}{ Household crime } & \multirow[b]{2}{*}{$\begin{array}{l}Z \text {-value for } \\
p \text { difference }\end{array}$} & \multicolumn{2}{|c|}{ Personal crime } & \multirow[b]{2}{*}{$\begin{array}{l}Z \text {-value for } \\
p \text { difference }\end{array}$} \\
\hline & $\begin{array}{l}\text { With } \\
\text { restrictions }\end{array}$ & $\begin{array}{l}\text { Without } \\
\text { restrictions }\end{array}$ & & $\begin{array}{l}\text { With } \\
\text { restrictions }\end{array}$ & $\begin{array}{l}\text { Without } \\
\text { restrictions }\end{array}$ & \\
\hline 0 & 6.1 & 4 & 2.04 & 59.9 & 52.5 & 3.18 \\
\hline 1 & 9.1 & 7.7 & 1.07 & 20.4 & 20.6 & -0.10 \\
\hline 2 & 11.3 & 7.7 & 2.62 & 9.5 & 11.2 & -1.19 \\
\hline 3 & 10.7 & 8.7 & 1.44 & 5.7 & 7.1 & -1.22 \\
\hline 4 & 11.7 & 9.7 & 1.38 & 1.7 & 3 & -1.83 \\
\hline 5 & 9.7 & 10.1 & -0.28 & 1.3 & 2 & -1.17 \\
\hline 6 & 6.6 & 7.8 & -0.99 & 0.8 & 1.5 & -1.40 \\
\hline 7 & 6.2 & 6.4 & -0.17 & 0.3 & 0.8 & -1.44 \\
\hline 8 & 5.2 & 5.2 & 0 & 0.1 & 0.3 & -0.95 \\
\hline 9 & 4.3 & 4.2 & 0.10 & 0.1 & 0.3 & -0.95 \\
\hline 10 & 3.8 & 4.2 & -0.43 & 0 & 0.3 & -1.65 \\
\hline 11 & 2.7 & 4.3 & -1.85 & 0 & 0 & 0 \\
\hline 12 & 2.4 & 2.8 & -0.53 & 0 & 0.1 & -0.95 \\
\hline 13 & 2.3 & 3.4 & -1.41 & 0 & 0 & 0 \\
\hline 14 & 1.2 & 2.3 & -1.79 & 0.1 & 0.1 & 0 \\
\hline 15 & 1.5 & 1.3 & 0.36 & 0 & 0 & 0 \\
\hline 16 & .8 & 1.4 & -1.22 & 0 & 0.1 & -0.95 \\
\hline $17+$ & 3.9 & 8.6 & -4.15 & 0 & 0.1 & -0.95 \\
\hline
\end{tabular}

highest predicted property crime are expected to have 4.4 and 3.6 more such and personal crimes, respectively, than the safest $10 \%$. Similar graphs across area deciles with respect to personal crime are available from the authors.

The study has been the first attempt to incorporate all distributional characteristics of jointly examined crime counts and further refinements are in order. For instance, covariance structure may be added to models with different marginal probabilities for zero events across crime types, such as the (zero-inflated) negative binomial (Wang, 2003), and compare the two bivariate count models via a bivariate extension of a recently developed score test (Xiang et al., 2007). The examination of correlated specific crime counts against individuals or households clustered within areas which would aid tailored crime prevention responses to individual needs can be achieved via hierarchical extensions of such multi-variate models for overdispersed counts.

To what use can the modelling be put? The resourcing of police force areas involves something close to a Catch 22 situation. The obvious basis of sourcing would be crime counts in an area. However, to use such a measure would risk local police inflating recorded crime counts to attract additional funding. The current basis of funding in England and Wales involves a painstaking but approximate regression approach (see Pease, 2008). The modelling approach taken here may, with appropriate testing, represent an advance. Further, each of the significant covariates challenges criminological theorizing, perhaps especially those in relation to composite crime. This is the wrong place and outlet 
to develop such theorizing, but the challenge should be taken up, by the writers no less than by others.

\section{References}

[1] Bowers, K. J., Johnson, S. D. \& Pease, K. (2004) Prospective hot-spotting: The future of crime mapping? Br. J. Criminol. 44, 641-658.

[2] Chenery, S., Ellingworth, D., Tseloni, A. \& Pease, K. (1996) Crimes which repeat: Undigested evidence from the British Crime Survey 1992. Int. J. Risk Secur. Crime Prev. 1, 207-216.

[3] Cohen, L. E. \& Felson, M. (1979) Social change and crime rates and trends: A routine activity approach. Am. Sociol. Rev. 44, 588-608.

[4] Davidian, M. \& Giltinan, D. M. (1995) Nonlinear Models for Repeated Measurement Data. Monographs on Statistics and Applied Probability 62. Chapman and Hall, London.

[5] Ellingworth, D., Hope, T., Osborn, D. R., Trickett, A. \& Pease, K. (1997) Prior victimisation and crime risk. Int. J. Risk Secur. Crime Prev. 2, 201-214.

[6] Ellingworth, D. \& Pease, K. (1998) Movers and breakers: household property crime against those moving home. Int. J. Risk Secur. Crime Prev. 3, 35-42.

[7] Farrell, G. \& K. Pease. (1993) Once Bitten, Twice Bitten: Repeat Victimisation and its Implications for Crime Prevention, Crime Prevention Unit Paper 46, Home Office, London.

[8] Farrell, G. \& Pease, K. (2001) (eds.) Repeat Victimization. Criminal Justice Press, Monsey, NY.

[9] Farrell, G., Tseloni, A. \& Pease, K. (2005) Repeat Victimization in the ICVS and NCVS. Crime Prev. Community Saf.: An Int. J. 7, 7-18.

[10] Felson, M. (1998) Crime and Everyday Life, 2nd ed. Pine Forge Press, Thousand Oaks, CA.

[11] Forrester, D., Chatterton, M. \& Pease, K. (1988) The Kirkholt Burglary Prevention Project, Rochdale, Crime Prevention Unit Paper 13. Home Office, London.

[12] Forrester, D., Frenz, S., O’Connell, M. \& Pease, K. (1990) The Kirkholt Burglary Prevention Project: Phase II, Crime Prevention Unit Paper 23. Home Office, London.

[13] Greene, W. H. (1997) Econometric Analysis. Prentice Hall, Upper Saddle River, NJ.

[14] Hales, J., Henderson, L., Collins, D. \& Becher, H. (2000) 2000 British Crime Survey (England and Wales): Technical Report. National Centre for Social Research, London.

[15] Hindelang, M., Gottrredson, M. R. \& Garofalo, J. (1978) Victims of Personal Crime: An Empirical Foundation for a Theory of Personal Victimisation, Ballinger, Cambridge, UK.

[16] Hope, T. (2007). The social epidemiology of crime victims. In: S. Walklate (editor), Handbook on Victims and Victimology, Willan, Uffculme, Devon, UK.

[17] Hope, T., Bryan, J., Trickett, A. \& Osborn, D. R. (2001) The phenomena of multiple victimisation. Br. J. Criminol. 41, 595-617.

[18] Hough, M. \& Mayhew, P. (1983) The British Crime Survey: First Report. Home Office Research Study no. 76, Her Majesty's Stationary Office, London.

[19] Juran J. M. (1951) Quality Control Handbook, McGraw-Hill, New York.

[20] Karlis, D. \& Ntzoufras, I. (2005) Bivariate Poisson and diagonal inflated bivariate Poisson regression models in R. J. Stat. Softw. 14. URL: http://www.jstatsoft.org

[21] Kennedy, L. W. \& Forde, D.R. (1990) Routine activities and crime: An analysis of victimisation in Canada. Criminology 28, 137-152.

[22] Kershaw, C., Budd, T., Kinshott, G., Mattinson, J., Mayhew, P. \& Myhill, A. (2000) The 2000 British Crime Survey England and Wales. Statistical Bulletin 18/00. Home Office, London.

[23] Kershaw, C., Chivite-Matthews, N., Thomas, C. \& Aust, R. (2001) The 2001 British Crime Survey Final Results, England and Wales. Home Office Statistical Bulletin 18/01. Home Office, London.

[24] Kershaw, C. \& Tseloni, A. (2005) Predicting crime rates, fear and disorder based on area information: Evidence from the 2000 British Crime Survey. Int. Rev. Victimol. 12, 295-313. 
[25] Lee, A. H., Wang, K., Yau, K. K. W., Carrivick, P. J. W. \& Stevenson, M. R. (2005) Modelling bivariate count series with excess zeros. Math. Biosci. 196, 226-237.

[26] Li, C., Lu, J., Park, J. P., Kim, K., Brinkley, P. A. \& Peterson, J. P. (1999) Multivariate zero-inflated Poisson models and their applications. Technometrics 41, 29-38.

[27] Lynn, P. \& Elliot, D. (2000) The British Crime Survey: A Review of Methodology. National Centre for Social Research, Paper 1974, March.

[28] Mcloughlin, L. M., Johnson, S. D., Bowers, K. J., Birks, D. J. \& Pease, K. (2007) Police perceptions of the long and short-term spatial distribution of residential burglary. Int. $J$. Police Sci. Manag. 9, 99-111.

[29] Nicholas, S., Kershaw, C. \& Walker, A. (editors) (2007) Crime in England and Wales 2006/07. Home Office Statistical Bulletin 11/07.

[30] Osborn, D. R., Ellingworth, D., Hope, T. \& Trickett, A. (1996) Are repeatedly victimised households different? J. Quant. Criminol. 12, 223-245.

[31] Osborn, D. R., Trickett, A. \& Elder, R. (1992) Area characteristics and regional variates as determinants of area property crime levels. J. Quant. Criminol. 8, 265-285.

[32] Osborn, D. R. \& Tseloni, A. (1998) The distribution of household property crimes. J. Quant. Criminol. 14, 307-330.

[33] Pease, K. (1998) Repeat Victimisation: Taking Stock. Crime Detection and Prevention Series Paper No. 90. Home Office, London.

[34] Pease K. (2008) The home office and the police: The case of the police funding formula. In: , A. McVean \& C. Harfield (editors), Handbook of Intelligent Policing, Wiley, Chichester, UK.

[35] Planty, M. \& Strom, K. J. (2007) Understanding the role of repeat victims in the production of annual victimization rates J. Quant. Criminol. 23, 179-200.

[36] ReIss, A. J. (1980) Victim proneness in repeat victimization by type of crime. In: S. Fienberg \& A. J. Reiss (editors), Indicators of Crime and Criminal Justice Quantitative Studies, Department of Justice, Washington, DC, pp. 41-53.

[37] Sampson, R. J. \& Groves, B. W. (1989) Community structure and crime: Testing social disorganization theory. Am. J. Sociol. 94, 774-802.

[38] Shaw, C. R. \& McKaY, M. D. (1942) Juvenile Delinquency and Urban Areas. Chicago University Press, Chicago, IL.

[39] ThORPe (2007) Multiple and repeat victimisation. In: K. Jansson, S. Budd, J. Lovbakke, S. Moley \& K. Thorpe (editors), Attirudes, Perceptions and Risks of Crime: Supplementary Volume 1 to Crime in England and Wales 2006/07, Home Office Statistical Bulletin 19/07. Home Office, London. pp. 81-98.

[40] Trickett, A., Osborn, D. \& Seymour, J. (1992) What is different about high crime areas? Br. J. Criminol. 32, 81-90.

[41] Trickett A., Osborn, D. R. \& Ellingworth, D. (1995) Property crime victimisation: The roles of individual and area influences. Int. Rev. Victimol. 3, 273-295.

[42] Tseloni, A. (2006). Multilevel modelling of the number of property crimes: Household and area effects. J. R. Stat. Soc. A 169, 205-233.

[43] Tseloni, A. Osborn, D. R., Trickett, A. \& Pease, K. (2002) Modelling property crime using the British Crime Survey: What have we learned? Br. J. Criminol. 42, 89-108.

[44] Venables, W. N., Smith, D. M. \& the R Development Core Team (2007) An Introduction to R: Notes on R: A Progamming Environment for Data Analysis and Graphics, Version 2.5.1 (2007-06-27), R Development Core Team, URL: http://www.r-project.org/

[45] WANG, P. (2003) A bivariate zero-inflated negative binomial regression model for count data with excess zeros. Econ. Lett. 78, 373-378.

[46] Wang, K., Lee, A. H., Yau, K. K. W. \& Carrivick, P. J. W. (2003) A bivariate zero-inflated Poisson regression model to analyse occupational injuries. Accid. Anal. Prev. 35, 625-629.

[47] Xiang, L., Lee, A. H., Yau, K. K. W. \& McLachlan, G. J. (2007) A score test for overdispersion in zero-inflated poisson mixed regression model. Stat. Med. 26, 1608-1622. 